\title{
Gas Desorption of Inner Coating Materials Used for Cathode Ray Tube* -Effect of exposure time in the atmosphere on gas desorption-
}

\author{
Masao HASHIBA*1, Yuko HIROHATA*1, Tomoaki HINO*1, \\ Hidekazu YAMADA*2, Akio KOIDE*2 and Yoshihiro KUBOTA*2 \\ ${ }^{*}$ Department of Nucleár Engineering, Hokkaido University, Sapporo, 060-8628, Japan \\ ${ }^{*}{ }_{2}$ Chemical Products Div., Hitachi Powdered Metals Co., Ltd., \\ Tako-machi, Katori-gun, Chibaken, 289-2247, Japan
}

(Received November 13, 2003, Accepted February 14, 2004)

For two types of inner coating material of cathode ray tube (CRT) with different composition of water glass, the effect of air exposure in the atmosphere on the gas desorption was examined by using thermal desorption spectroscopy. The major outgassing species during the heating up to $773 \mathrm{~K}$ were $\mathrm{CO}_{2}$ and $\mathrm{H}_{2} \mathrm{O}$ in both the types. In the thermal desorption spectra of $\mathrm{CO}_{2}$ and $\mathrm{H}_{2} \mathrm{O}$, a large desorption peak was observed at approximately $400 \mathrm{~K}$. In both the materials, the amount of desorbed gases saturated at the exposure time of $1 \mathrm{~h}$. Total amount of desorbed $\mathrm{CO}_{2}$ and $\mathrm{H}_{2} \mathrm{O}$ for the type with water glass content of $\left(\mathrm{K}_{2} \mathrm{O}+\mathrm{Li}_{2} \mathrm{O}\right) \cdot 3.8 \mathrm{SiO}_{2} \cdot 4 \mathrm{H}_{2} \mathrm{O}$ was approximately a half of that for the type with water glass content of $\mathrm{K}_{2} \mathrm{O} \cdot 3.8 \mathrm{SiO}_{2} \cdot 4 \mathrm{H}_{2} \mathrm{O}$. The surface morphology of the former type showed fine structure compared with that of the latter type. If the former type is used for the inner coating material, the manufacturing process of CRT may be shortened compared with that of the latter type.

\section{Introduction}

A large cathode ray tube (CRT) for color television with a high performance has been still now developed. In order to lengthen the lifetime of CRT, the residual gas in the CRT has to be reduced for a depletion of the cathode to be suppresed. In a manufacturing process, the baking treatment has been conducted in the atmosphere and followed by in a vacuum. The maximum baking temperature is taken $673 \mathrm{~K}$. After the baking in vacuum, residual gases such as $\mathrm{H}_{2}$ and $\mathrm{H}_{2} \mathrm{O}$ are gettered by flashing Ba metal ${ }^{1)}$. Major gas source of the CRT is the inner coating material ${ }^{2}$. Carbon based material has been used as the inner coatings to control the electrical conductivity at the surface. The electrostatic potential profile and electrical insulation depend on the conductivity. The composition of the inner coatings has been empirically determined so far. We studied on the gas desorption and adsorption properties for inner coating materials with different composition $^{3-8)}$.

In this study, we examined the effect of air exposure time on gas desorption of inner coating material with different water glass composition, us-

* 平成15年11月13日 第44回真空に関する連合講演会で発表 ing a thermal desorption spectroscopy (TDS). Since the structure of the coating film depends on the composition of the inner coating material ${ }^{3-6)}$, the surface morphology was also examined by scanning electron microscope (SEM) and atomic force microscope (AFM).

\section{Experiment}

Inner coating material consisted of carbon powder with alkaline sol mixture, $\mathrm{TiO}_{2}$ powder and water glass. Two types of inner coating material were prepared by using different water glass. The mass ratio of water glass were kept $32 \mathrm{wt} . \%$. Two types of water glass, i.e., type $\mathrm{A}$ and type $(\mathrm{A}+\mathrm{B})$, were employed. The composition of water glass of type $A$ was $\mathrm{K}_{2} \mathrm{O} \cdot 3.8 \mathrm{SiO}_{2} \cdot 4 \mathrm{H}_{2} \mathrm{O}$ and that of type (A $+\mathrm{B})$ was $\left(\mathrm{K}_{2} \mathrm{O}+\mathrm{Li}_{2} \mathrm{O}\right) \cdot 3.8 \mathrm{SiO}_{2} \cdot 4 \mathrm{H}_{2} \mathrm{O}$. Inner coating material was coated on the entire surface of 304 stainless steel plate with size of $20 \mathrm{~mm} \times 60 \mathrm{~mm} \times$ $0.05 \mathrm{~mm}$ by using a brush. The coating thickness was $3-5 \mu \mathrm{m}$. The weight of the inner coating was 11-18 mg. After the coating, the sample was dried at room temperature for $1 \mathrm{~h}$. And then, the sample was heated at $723 \mathrm{~K}$ for $1 \mathrm{~h}$ in the atmosphere. After the heat treatment, the sample was exposed to the atmosphere with humidity $50 \%$ at $303 \mathrm{~K}$. The exposure time was changed from $10 \mathrm{~min}$ to $24 \mathrm{~h}$. In 
order to measure the absorption amount of gas, the sample was placed in a TDS apparatus ${ }^{8}$. The TDS chamber was evacuated by a turbomolecular pump (TMP) and a rotary pump (RP). The ultimate pressure was $3 \times 10^{-5} \mathrm{~Pa}$. The total and partial pressures were monitored by a B-A gauge and a quadrupole mass spectrometer (QMS), respectively. The effective pumping speed was measured using a standard leak. The effective pumping speeds for $\mathrm{CO}_{2}$ and $\mathrm{H}_{2} \mathrm{O}$ were estimated as $0.044 \mathrm{~m}^{3} / \mathrm{s}$ and 0.055 $\mathrm{m}^{3} / \mathrm{s}$, respectively. The sample was resistively heated from RT $(296 \mathrm{~K})$ to $773 \mathrm{~K}$ in the vacuum with a heating rate of $0.167 \mathrm{~K} / \mathrm{s}$. During the TDS measurement the sample temperature was monitored by a thermocouple spot-welded on the sample.

\section{Results}

Figure 1 shows the SEM photographs of both the samples of type A and type $(A+B)$. No significant difference in the surface morphology between the them was observed. However, many small cracks were observed in the $(\mathrm{A}+\mathrm{B})$ type. We also observed the surface morphology by using AFM (Fig.
2). The surface of the $(A+B)$ type had fine structure compared with that of $A$ type sample. In addition, the effective surface area of the $(A+B)$ type was approximately double of that of the $A$ type ${ }^{8)}$. The observation by AFM is roughly consistent with that of the effective surface area. Thus, it is regarded that the $(A+B)$ type is more porous than that of the A type.

In our previous study, it was found that the amounts of gas desorption and absorption significantly depended on the composition of water glass $^{3-6}$. In addition, the surface morphology and effective surface area of the inner coating material also depended on the composition of water glass $^{3-6)}$.

Figure 3 shows the thermal desorption spectra of the A type after air exposure for $10 \mathrm{~min}$ (a) and 30 min (b). The major gas species desorbed from the sample were $\mathrm{H}_{2} \mathrm{O}$ and $\mathrm{CO}_{2}$. In the TDS spectra of $\mathrm{H}_{2} \mathrm{O}$ and $\mathrm{CO}_{2}$, a large desorption peak was observed at approximately $400 \mathrm{~K}$. The spectrum of $\mathrm{H}_{2}$ $\mathrm{O}$ had a broad peak, although that of $\mathrm{CO}_{2}$ was sharp. In the spectrum of $\mathrm{CO}_{2}$, a second peak was
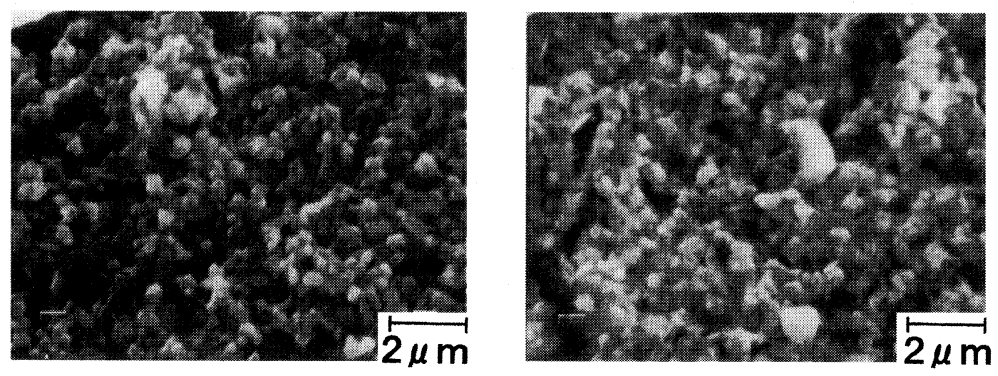

Fig. 1 SEM photographs for A type and $(A+B)$ type.
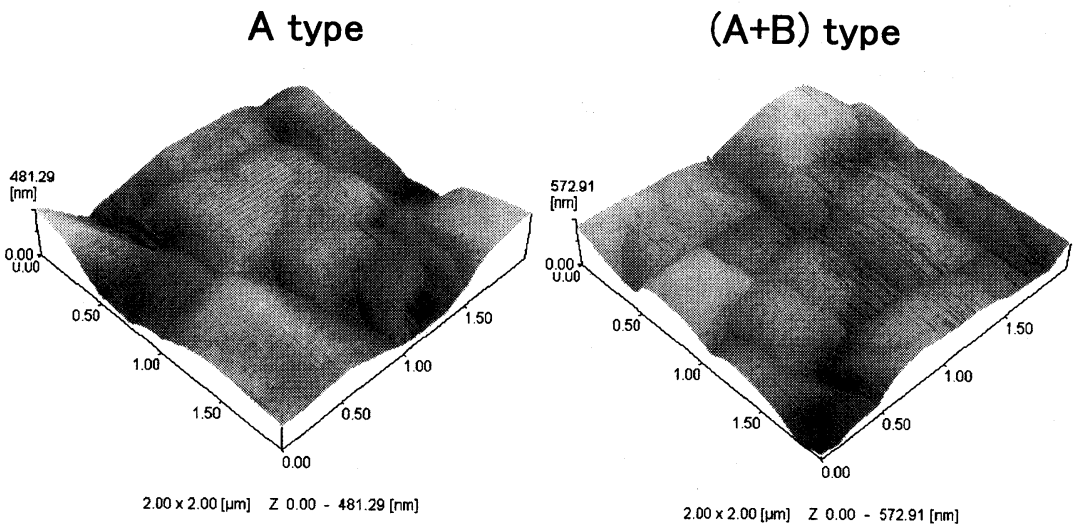

Fig. 2 AFM photographs of A type and $(A+B)$ type. 
(a)

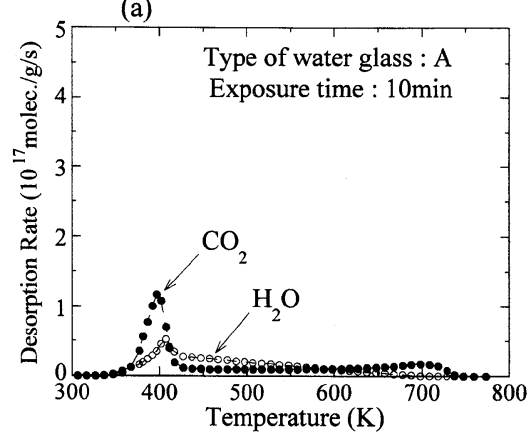

(b)

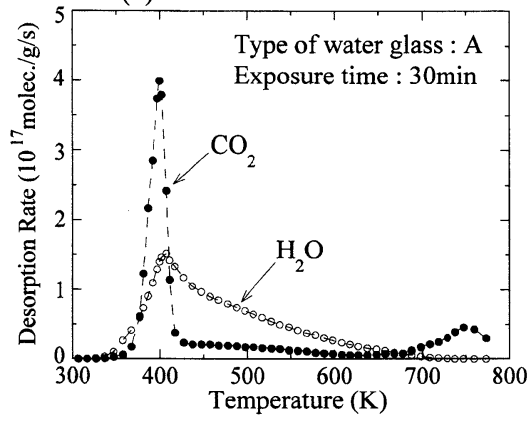

Fig. 3 Thermal desorption spectra of $\mathrm{H}_{2} \mathrm{O}$ and $\mathrm{CO}_{2}$ of A type after air exposure with exposure time for $10 \mathrm{~min}(\mathrm{a})$, and for $30 \mathrm{~min}$ (b).

observed at $710-760 \mathrm{~K}$. The amount of desorbed $\mathrm{H}_{2}$ $\mathrm{O}$ and $\mathrm{CO}_{2}$ increased with the exposure time in the atmosphere. In the $(A+B)$ type, the spectra were roughly similar with the case of the A type, although the desorption amount was small.

Figure 4 shows the thermal desorption spectra of $\mathrm{H}_{2} \mathrm{O}$ and $\mathrm{CO}_{2}$ for the A type (a) and (A+B) type (b) after air exposure for $30 \mathrm{~min}$. The desorption amounts of $\mathrm{H}_{2} \mathrm{O}$ and $\mathrm{CO}_{2}$ for the $(\mathrm{A}+\mathrm{B})$ type were smaller than those of $A$ type. The second peak of $\mathrm{CO}_{2}$ spectrum in the $(\mathrm{A}+\mathrm{B})$ type appeared at a lower temperature region, $580 \mathrm{~K}$. The amounts of desorbed gases were obtained by integrating for the desorption rate with respect to the heating time up to $773 \mathrm{~K}$. Figure 5 shows the desorption amounts of $\mathrm{H}_{2} \mathrm{O}$ and $\mathrm{CO}_{2}$ as a function of the exposure time in the atmosphere. The desorption amounts of $\mathrm{H}_{2} \mathrm{O}$ and $\mathrm{CO}_{2}$ increased with the exposure time in both the types, and saturated for $1 \mathrm{~h}$. In the manufacture process, the air exposure time after baking is taken shorter than $1 \mathrm{~h}$. In this case, the desorption amount of the $(\mathrm{A}+\mathrm{B})$ type is approximately a half of that of A type. The viscosity of the water glass used for the $(\mathrm{A}+\mathrm{B})$ type is smaller than that of $\mathrm{A}$ type. The gas absorption mainly takes place in the (a)

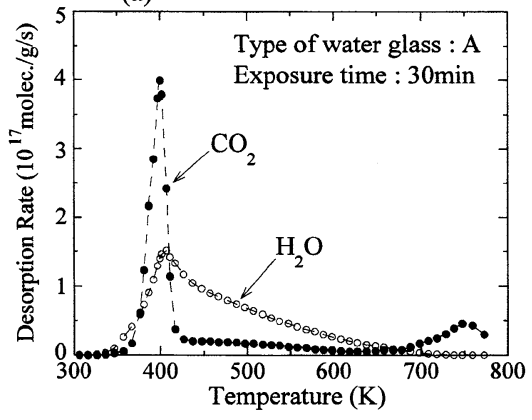

(b)

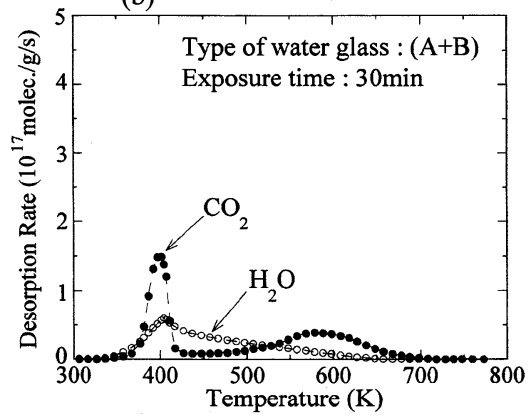

Fig. 4 Thermal desorption spectra of $\mathrm{H}_{2} \mathrm{O}$ and $\mathrm{CO}_{2}$ for A type (a) and (A+B) type (b) after air exposure for $30 \mathrm{~min}$ at $303 \mathrm{~K}$.

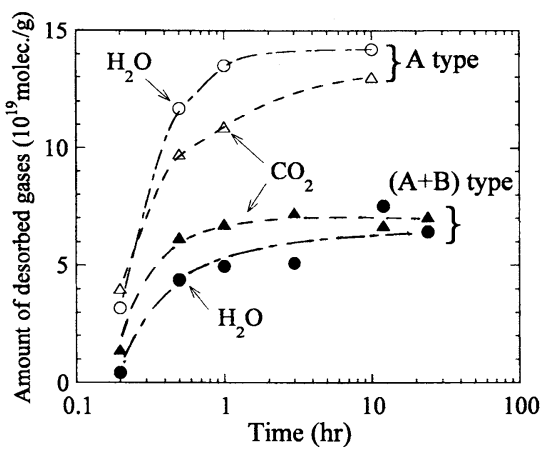

Fig. 5 Desorption amounts of $\mathrm{H}_{2} \mathrm{O}$ and $\mathrm{CO}_{2}$ versus air exposure time.

carbon powders. Hence, in the case of the $(A+B)$ type, the surface of carbon powders might be sufficiently coated with the water glass. This may be a reason that the gas absorption amount of the (A + B) type was smaller.

\section{Conclusion}

For two types of inner coating material with different composition of water glass, the effect of 
air exposure time in the atmosphere on the gas desorption was examined using TDS.

Major gas species desorbed from both the types were $\mathrm{H}_{2} \mathrm{O}$ and $\mathrm{CO}_{2}$. The desorption amount of gases saturated at exposure time of $1 \mathrm{~h}$ in both the types. The desorption amount of gases for the $(\mathrm{A}+$ $B)$ type was a half of that for the A type. The surface morphology of the $(A+B)$ type had fine structure, compared with that of the A type.

If the $(\mathrm{A}+\mathrm{B})$ type is employed in the manufacture process, the baking temperature can be reduced and the pumping time can be shortened, compared with a case of the A type.

\section{References}

1) For example, P. della Porta: Proc. $4^{\text {th }}$ Inter. Symposium on Residual Gases in Electron Tubes., Florence, Italy, 1971, p. 3.
2) Committee of application of Vacuum Technology, Ed.: Application of Vacuum Technology, Sangyo Gijyutsu Service Center, 1990, p. 519 (in Japanease).

3) M. Hashiba, Y. Hirohata, T. Hino, H. Shinbori, S. Deyama and H. Chiyoda: J. Vac. Soc. Jpn., 41 (1998) 440.

4) M. Hashiba, T. Hino, Y. Hirohata, H. Shinbori, S. Deyama and H. Chiyoda: Carbon, 36 (1998) 1133.

5) M.Hashiba, T. Hino, Y. Hirohata, H. Shinbori, S. Deyama and H. Chiyoda: Thin Solid Films, 332 (1998)141.

6) M. Hashiba, Y. Hirohata, T. Hino, H. Shinbori, S. Deyama and H. Chiyoda: J. Vac. Soc. Jpn., 42 (1999) 1100.

7) H. Shinbori, S. Deyama, M. Hashiba, Y. Hirohata, and T. Hino: J. Vac. Soc. Jan., 44 (2001) 592.

8) M. Hashiba, Y. Hirohata, T. Hino, H. Yamada, A. Koide and Y. Kubota: J. Vac. Soc. Jan., 46 (2003) 539. 